\title{
PREVALENCE OF RISK FACTORS FOR NON-COMMUNICABLE DISEASES FOR NEW PATIENTS REPORTING TO KORLE-BU TEACHING HOSPITAL
}

\author{
F. NELSON ${ }^{1}$, K. M. NYARKO ${ }^{2}$ and F.N. BINKA ${ }^{3}$ \\ ${ }^{1}$ Pharmacy Department, Korle Bu Teaching Hospital, P. O. Box KB 77, Korle-Bu, Accra, Ghana, \\ ${ }^{2}$ Department of Epidemiology and Disease Control, School of Public Health, P. O. Box 13, Legon, Accra, \\ Accra, Ghana ${ }^{3}$ School of Public Health, University Of Ghana, P.O. Box 13, Legon, Accra, Ghana
}

DOI: $h t t p: / / d x . d o i . o r g / 10.4314 / g m j . v 49 i 1.3$

Corresponding Author: Mrs. Frempomaa Nelson

Email:frempy2001@yahoo.com

Conflict of Interest: None declared

\section{SUMMARY}

Background: The risk factors of Noncommunicable diseases (NCDs) are not routinely monitored, especially among populace reporting to hospitals to detect and also advise on preventive measures, a key strategy to reducing the impact of NCDs on the Health Care System and population.

Methods: A cross-sectional survey was carried out between the months of May and June, 2010 among a sample representative of the medical and surgical out-patients population to determine the prevalence of certain risk factors of non-communicable diseases (NCDs). Participants $(n=230)$ were selected by systematic random sampling. Standardised international protocols were used to measure the prevalence of smoking, alcohol consumption, physical inactivity, obesity, raised blood pressure, raised blood glucose and total cholesterol.

Results: The obesity level of the study population was $40.4 \%$ with $54 \%$ being overweight. Tobacco use among the respondents was $4.8 \%$. Alcohol consumption was $64.8 \%$, with $54.3 \%$ of the study population being physically inactive. Almost $48 \%$ and $70.9 \%$ of the participants consumed fruits and vegetables respectively, at least three days in a week. The prevalence of hypertension was $33.6 \%$ for men and $35.2 \%$ for women. The prevalence of raised glucose and total blood cholesterol level among the study population was $6.5 \%$. Almost $62 \%$ of the participants had a combination of three or more risk factors.

Conclusion: The prevalence of the significant risk factors in this study were physical inactivity (54.3\%), alcohol consumption (64.8\%), overweight $(54 \%)$, obesity $(40.4 \%)$ and raised blood pressure (34.3\%). Hospitals should therefore include NCD risk factor monitoring as part of routine services.
Keywords: Non-communicable disease, obesity, blood pressure, blood sugar, blood cholesterol, physical inactivity, Korle-Bu Teaching Hospital

\section{INTRODUCTION}

Non-communicable diseases killed tens of millions of people in 2008, and a large proportion of these deaths occurred before the age of 60 , during the most productive period of life. ${ }^{1}$ The magnitude of these diseases continues to rise, especially in low- and middle-income countries. ${ }^{1}$ Non-communicable diseases are chronic conditions that do not result from infectious process. These conditions cause dysfunction, or impairment in the quality of life, and they usually develop over relatively long periods and ultimately lead to death if not controlled. ${ }^{2}$

Non-communicable diseases (NCDs) include coronary heart diseases, diabetes, stroke, peripheral vascular disease, injuries, cancers and Chronic Obstructive Pulmonary Disease (COPD). It is important that these diseases are detected early in order to mitigate their effect on health. Fortunately there are several risk factors that predispose the population to NCDs. A number of these risk factors can be prevented or completely eliminated such as tobacco use, alcohol consumption, elevated blood pressure, elevated lipid levels, overweight, low fruit/vegetable intake, physical inactivity, and elevated blood glucose. Clustering of these risk factors significantly increases the risk of morbidity and mortality from cardiovascular diseases. $^{3}$

In Ghana, the work by Albert Amoah and his team in urban and rural Accra showed that the overall prevalence of overweight and obesity was $23.4 \%$ and $14.1 \%$ respectively among adults aged 25 years and above The rates were higher in females than in men. ${ }^{4}$ 
The extent of smoking among Ghanaian adults measured by the 2008 Ghana Demographic Health Survey (GDHS) revealed that smoking in Ghana is higher among men than women. Ninety-three percent of men said they did not use tobacco at all and only $6 \%$ of men aged 15-49years said they currently smoked cigarettes.

Diabetes that is the result of elevated blood glucose has been determined in Ghana to be $6.3 \%$ in Greater Accra Region. ${ }^{6} \quad$ Another important NCD is hypertension. Addo and her colleagues report the prevalence of hypertension among four rural community residents in Ga District of Ghana to be $25.4 \%$. Of those with hypertension, only $32.3 \%$ had prior knowledge of their condition, and less than half of these were on treatment. ${ }^{7}$ Prevalence of physical inactivity among the respondents in this study was $54.30 \%$ which was lower than that of the Ghana STEPS Survey (76.7\%) and higher than similar study conducted in Vietnam with $34.71 \%{ }^{11}$ and rural area of Kerala, India with $9.5 \% .^{10}$

The prevalence of obesity, which is a potentially modifiable risk factor for non-communicable diseases $^{15}$ in the study was $40.4 \%$, which was greater than $14.1 \%$ in a study in rural and urban Accra ${ }^{4}$ and 5.5\% among Ghanaians ${ }^{16}$ as well as $9 \%$ in the GDHS. ${ }^{5}$ These results indicate a growing prevalence of these risk factors among the population, which contribute to the burden of NCD in the population. There are fewer studies of chronic disease experiences compared to epidemiological studies, ${ }^{27}$ hence these risk factors are not routinely monitored to detect and also advise on preventive measures, a key strategy to reducing the impact of NCDs on the Health Care System and population.

Most studies involving risk factors of NCDs are community-based with the hospitals being overlooked $^{4,6,7,16}$ Hospitals are one key area to this routine monitoring among the patients reporting to the hospitals and though instruments are available to measure and monitor, they have been overlooked. There is therefore the need to act to avoid missed opportunities to detect risk factors and also to provide education to patients. We therefore set up to determine the risk factors of NCD among the new patient population reporting to the surgical and medical out-patients departments.

This study was undertaken to determine the prevalence of (a) behavioural risk factors (physical inactivity, alcohol consumption, tobacco use) and (b) biological risk factors (raised blood pressure, overweight, raised blood sugar, raised blood lipid levels) among new patients reporting to the surgical and medical OPD of the KBTH.

\section{METHOD}

\section{Study area:}

The Korle- $\mathrm{Bu}$ Teaching Hospital (KBTH) is a National Referral Hospital as well as the Teaching Hospital for the University of Ghana Medical School. It was established to provide tertiary health care for all Ghanaians, provide facilities to educate and train health professionals, conduct research and provide specialist outreach services to all Ghanaians in other regions and districts. ${ }^{8}$ The Surgical and Medical Outpatients Departments usually attend to referrals from various health institutions.

The Department of Surgery usually attends to referrals including breast cancers, neurological and genitourinary conditions as well as general surgery and has an OPD attendance of 408 new patients monthly (according to Statistical Department, KBTH). Disease conditions such as cardiovascular, renal disease, skin disorders, asthma, prostate cancer and cerebrovascular accident(stroke) are usually referred to the Medical Outpatients Department, which has an OPD attendance of 330 new patients monthly(according to Statistical Department, KBTH).

\section{Study population:}

The study population selected was composed of 230 new patients reporting to the Surgical and Medical Out-patients Departments of the Korle-Bu Teaching Hospital $(50 \%$ of cases from each department) over a four- week period $\left(21^{\text {st }}\right.$ May $-21^{\text {st }}$ June, 2010) aged between 18-80 years. They were grouped into three (under 25years: prior to fertility group; 25-44years: fertility group and above 44years: post fertility group), to allow estimation of key variables with high precision for both men and women, since there was not much differences in the 10-year groupings.

\section{Study design and sampling procedure:}

This was a hospital- based cross-sectional survey in which a sample representative of the medical and surgical outpatients population was surveyed. The medical department has four wards whiles the surgical department has five wards. Therefore patients were selected to reflect a fair distribution among the wards and after randomly selecting the first patient, every third patient was selected hence sampling by stratification and systematic random sampling were used.

Patients had their body weight, body height, waist, hip and blood pressure measured to check their body mass index, waist-to-hip ratio and raised blood pressure after completing the questionnaire. Questionnaire developed was based on the WHO Stepwise Approach. 
Also patients who had fasted for 10- 12 hours and gave their consent had their blood samples taken to test for fasting blood glucose and blood lipids, after completing the questionnaire.

\section{Definition of risk factors}

1. Obesity- Body Mass Index (BMI), which is the ratio of weight (in kilograms) and the square of the height (in metres), $\geq$ $30 \mathrm{~kg} / \mathrm{m} 2$, was measured using a weighing scale and wall height measurements respectively.

- Central Obesity: Waist/Hip ratio > 0.85 for women and 0.90 for men

- Overweight : BMI between 25$29.9 \mathrm{~kg} / \mathrm{m}^{2}$

- Normal weight: BMI between 18.5$24.9 \mathrm{~kg} / \mathrm{m}^{2}$

- Underweight: $\mathrm{BMI}<18.5 \mathrm{~kg} / \mathrm{m}^{2}$

2. Tobacco Intake - smoking, chewing, and ingestion of tobacco or tobacco-containing products

3. Alcohol Consumption - Consuming alcohol at least once a month.

4. Physical Inactivity - Spending less than half the day on one's feet or leading a sedentary lifestyle.

5. Physical Activity- Spending more than half the day on one's feet or getting involved in at least 30 minutes of regular moderate to vigorous activity at least 5 days in a week.

6. Diabetes (Elevated blood glucose)Fasting blood glucose $\geq 6.1 \mathrm{mmol} / \mathrm{L}$.

7. Hypercholesterolemia-Total cholesterol $>5.2 \mathrm{mmol} / \mathrm{L}$.

8. Raised triglyceride level - Triglyceride level $>1.7 \mathrm{mmol} / \mathrm{L}$.

9. Low High Density Lipoprotein (HDL) cholesterol- HDL $<1.15$.

10. Raised Low Density Lipoprotein (LDL) cholesterol- LDL $>2.6 \mathrm{mmol} / \mathrm{L}$.

11. Hypertension (Elevated blood pressure)Systolic blood pressure $\geq 140 \mathrm{mmHg}$ and/ or diastolic blood pressure $\geq 90 \mathrm{mmHg}$ (U.S Dept. of Health, JNC Report 2004) .

12. Some education- those who had completed primary, junior and senior secondary schools

13. Highest education - completion of polytechnic or university (first, second or doctorate degree).

14. Single patients- comprises of divorced, never married and widowed.
15. Employed- working as a government or nongovernment employee

16. Unemployed- student, retiree or participants currently not working.

Ethical Clearance: Ethical clearance was obtained from the Ethical Committee of the Ghana Health Service and permission also sought from the Director of Medical Affairs of the KBTH. Participants were given consent forms to fill and were seen privately in the consulting rooms.

They were also informed that the procedure was for research purposes and would possibly be published.

Data analysis: Analysis was performed using SPSS (R) version 16.0. Logistic Regression was used to determine associations between the behavioural, physical and biochemical measurements with demographic characteristics.

\section{RESULTS}

The social and demographic characteristics are presented in Table 1 . The sample was made up of $45.7 \%$ females with majority of the respondents reported to have had some level of education: $73.5 \%$ completed basic/secondary education and $15.7 \%$ completed tertiary education.

Table 1 Socio-demographic characteristics of the study population

\begin{tabular}{|l|l|l|}
\hline Variable & Total (N= 230) & N \% \\
\hline Sex & & \\
\hline Male & 125 & 54.3 \\
\hline Female & 105 & 45.7 \\
\hline Age groups (years) & & \\
\hline Under 25 & 31 & 13.5 \\
\hline 25-44 & 82 & 35.7 \\
\hline 45 and above & 117 & 50.8 \\
\hline Level of education & & \\
\hline Primary/Secondary & 169 & 73.5 \\
\hline $\begin{array}{l}\text { Tertiary } \\
\text { No education }\end{array}$ & 36 & 15.7 \\
\hline Marital status & & 10.8 \\
\hline Single & 103 & \\
\hline $\begin{array}{l}\text { Currently married } \\
\text { Main work status }\end{array}$ & 127 & 44.8 \\
\hline $\begin{array}{l}\text { Employed } \\
\text { Unemployed }\end{array}$ & 159 & 55.2 \\
\hline
\end{tabular}


Fifty-five percent of the population were currently married while almost $45 \%$ were single (divorced, widowed and never married). More females $(65.6 \%)$ were married compared to men (data not shown in Table 1).

Table 2 Prevalence of NCD risk factors in OPD Hospital attendants in May 2010

\begin{tabular}{|l|l|l|l|}
\hline & \multicolumn{3}{|l|}{ Prevalence (\%) } \\
\hline & $\begin{array}{l}\text { Population } \\
\text { prevalence }\end{array}$ & $\begin{array}{l}\text { Male } \\
(\mathbf{N = 1 2 5})\end{array}$ & $\begin{array}{l}\text { Female } \\
\text { (N=105) }\end{array}$ \\
\hline Tobacco use & 4.8 & 6.4 & 2.9 \\
\hline Alcohol consumption & 64.8 & 72.0 & 56.2 \\
\hline Physical inactivity & 54.3 & 44.8 & 65.7 \\
\hline Overweight & 54.0 & 44.7 & 66.6 \\
\hline Obesity & 40.4 & 36.0 & 45.7 \\
\hline Raised blood pressure & 34.3 & 33.6 & 35.2 \\
\hline Raised blood glucose & 6.5 & 8.2 & 5.5 \\
\hline Raised total cholesterol & 6.5 & 4.56 & 9.1 \\
\hline
\end{tabular}

Table 2 shows the prevalence of NCD risk factors in OPD Hospital attendants in May 2010. The significant risk factors in the study were alcohol consumption $(64.8 \%)$, physical inactivity (54.3\%) and overweight $(54 \%)$ and raised blood pressure $(34.3 \%)$

Table 3 Prevalence of alcohol intake among study population

\begin{tabular}{|c|c|c|c|c|}
\hline 2 & Yes & No & Prevalence & $\begin{array}{l}\text { Prevalence odds } \\
\text { ratio }(95 \% \mathrm{CI})\end{array}$ \\
\hline \multicolumn{5}{|l|}{ Sex } \\
\hline \begin{tabular}{l|l} 
& Male
\end{tabular} & 90 & 35 & 0.72 & $* 2.00(1.12,3.60)$ \\
\hline Female & 59 & 46 & 0.56 & 1 \\
\hline \multicolumn{5}{|l|}{ Age group } \\
\hline \begin{tabular}{l|l} 
& Under 25 \\
\end{tabular} & 11 & 20 & 0.35 & $* 0.22(0.09,0.54)$ \\
\hline $25-44$ & 54 & 28 & 0.66 & $0.76(0.39,1.46)$ \\
\hline \begin{tabular}{l|l} 
& 45 and above \\
\end{tabular} & 84 & 33 & 0.72 & 1 \\
\hline \multicolumn{5}{|l|}{ Level of education } \\
\hline None & 12 & 13 & 0.48 & $0.66(0.21,2.08)$ \\
\hline Some education & 116 & 53 & 0.69 & $1.56(0.70,3.47)$ \\
\hline 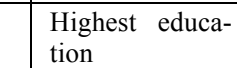 & 21 & 15 & 0.58 & ( \\
\hline \multicolumn{5}{|l|}{ Marital status } \\
\hline Single & 62 & 41 & 0.6 & $0.70(0.39,1.24)$ \\
\hline \begin{tabular}{l|l}
$\begin{array}{l}\text { Currently mar- } \\
\text { ried }\end{array}$ &
\end{tabular} & 87 & 40 & 0.69 & 年, \\
\hline \multicolumn{5}{|l|}{ Work status } \\
\hline Unemployed & 35 & 36 & 0.49 & $0.38(0.21,0.71)$ \\
\hline Employed & 114 & 45 & 0.72 & 1 \\
\hline
\end{tabular}

More people were overweight (54\%) compared to obese $(40.4 \%)$. Majority of the obese respondents were above 44years of age. The prevalence of raised blood glucose and raised total cholesterol were similar $(6.5 \%)$. This was made up of $2.9 \%$ of females and $6.4 \%$ of males. Tobacco use among respondents started within the age group of 12-22years.

Tables 3 and 4 show prevalence and prevalence odds ratio (POR) between some of the risk factors measured (using $95 \%$ confidence interval).

Table 4 Prevalence of raised blood pressure among study population

\begin{tabular}{|c|c|c|c|c|c|}
\hline & & Yes & No & Prevalence & $\begin{array}{l}\text { Prevalence odds } \\
\text { ratio }(95 \% \mathrm{CI})\end{array}$ \\
\hline \multicolumn{6}{|l|}{$\begin{array}{l}\text { Sex of } \\
\text { patient }\end{array}$} \\
\hline & Male & 42 & 83 & 0.34 & $0.93(0.52,1.67)$ \\
\hline & Female & 37 & 68 & 0.35 & 1 \\
\hline \multicolumn{6}{|c|}{ Age groups } \\
\hline & Under 25 & 7 & 24 & 0.23 & $* 0.34(0.12,0.91)$ \\
\hline & $25-44$ & 18 & 64 & 0.22 & $* 0.33(0.16,0.65)$ \\
\hline & 45 and above & 54 & 63 & 0.46 & 1 \\
\hline \multicolumn{6}{|c|}{ Alcohol intake } \\
\hline & Yes & 51 & 98 & 0.34 & $0.99(0.54,1.81)$ \\
\hline & No & 28 & 53 & 0.35 & 1 \\
\hline \multicolumn{6}{|c|}{ Frequency of fruit intake } \\
\hline & Never & 8 & 22 & 0.27 & $0.59(0.22,1.55)$ \\
\hline & $\begin{array}{l}1-2 \text { days per } \\
\text { week }\end{array}$ & 29 & 61 & 0.32 & $0.77(0.41,1.44)$ \\
\hline & $\begin{array}{l}>3 \text { days per } \\
\text { week }\end{array}$ & 42 & 68 & 0.38 & 1 \\
\hline \multicolumn{6}{|c|}{ Physically active } \\
\hline & Yes & 36 & 69 & 0.34 & $0.99(0.56,1.78)$ \\
\hline & No & 43 & 82 & 0.34 & 1 \\
\hline
\end{tabular}

However analysis to determine the associations between the risk factors shows that significant relationship was evident between raised blood pressure with the age groups, though providing a protective effect. For age group under 25 years, POR was $0.34(95 \% \mathrm{CI} 0.12,0.91)$ and for respondents between $25-44$ years, POR was $0.33(95 \% \mathrm{CI}$ $0.16,0.65)$.

However no significant relationship was found between obesity with age. Significant association was also evident between alcohol consumption and sex of participants with POR of $2.00(95 \%$ CI 1.12, 3.60), with males consuming more alcohol than females.

POR was $0.22(95 \%$ CI $0.09,0.54)$ for participants under 25 years of age and $0.38(95 \% \mathrm{CI} 0.21,0.71)$ for unemployed participants who consumed alcohol, showing a statistical significance but no statistically significant relationship was 
evident between alcohol consumption with marital status and educational level.

For the purpose of this study, individuals who spent more than half the day on their feet or involved in at least 30minutes of regular moderate to vigorous activity at least 5 days in a week, were defined as physically active. No significant relationship was evident between physical inactivity and age or marital status.

Fasting plasma glucose $\geq 6.1 \mathrm{mmol} / \mathrm{L}$ was defined in this study as raised blood glucose or diabetes. In the study, the lipid prolife analyzed was made up of total cholesterol, triglycerides, HDL-cholesterol and LDL-cholesterol. The prevalence of low HDLcholesterol was highest with $53.64 \%$ and a significant relationship was evident between raised LDL-cholesterol and sex of respondent with females having a prevalence of $10 \%$, almost twice that of the male prevalence $(5.65 \%)$.

In the study, hypertension was defined as respondents having a systolic blood pressure $\geq 140$ $\mathrm{mmHg}$ and /or diastolic blood pressure $\geq 90 \mathrm{mmHg}$ ${ }^{9}$ or using of blood pressure-lowering medications for hypertension.

Table 5 shows the prevalence of combined risk factors. Out of the 230 participants, 7 had a combination of tobacco, alcohol use and physical inactivity; 41 had a combination of overweight/obesity and raised blood pressure and 3 had a combination of raised blood glucose and raised total cholesterol. Ninety-one had a combination of at least three risk factors other than i, ii and iii as shown in Table 3.

Table 5 Prevalence of combined risk factors

\begin{tabular}{|l|l|l|}
\hline & $\begin{array}{l}\text { Total } \\
(\mathbf{2 3 0})\end{array}$ & $\begin{array}{l}\text { Prevalence } \\
\text { (\%) }\end{array}$ \\
\hline (i) Behavioural measurements & & \\
\hline $\begin{array}{l}\text { Tobacco+ Alcohol consumption+ Physical } \\
\text { inactivity }\end{array}$ & 7 & 3.04 \\
\hline (ii) Physical measurements & 41 & 17.83 \\
\hline $\begin{array}{l}\text { Obesity/overweight+ Raised blood pres- } \\
\text { sure }\end{array}$ & 3 & 1.30 \\
\hline (iii) Biochemical measurements & 91 & 39.57 \\
\hline $\begin{array}{l}\text { Raised blood glucose+ raised total choles- } \\
\text { terol } \\
\begin{array}{l}\text { Combination of at least 3 risk factors other } \\
\text { than i,ii and iii }\end{array}\end{array}$ & \\
\hline
\end{tabular}

Almost $62 \%$ of the participants had raised risk, defined as combination of three or more risk factors. None of the participants had all the risk factors.

\section{DISCUSSION}

The risk factors of today are the diseases of tomorrow. Identifying these risk factors in populations occupies a central place in the surveillance system because of the importance of the lag time between exposure and disease. Therefore, public health strategies have to be driven by the motive of identifying risk factors in populations, and countries need to know the profile of risk factors of populations in different settings. ${ }^{1}$ There are not many comprehensive studies done in Ghana on NCD risk factors.

The prevalence of tobacco use, alcohol consumption, overweight and physical inactivity were 4.8\%, 64.8\%, $54.0 \%$ and $54.3 \%$ respectively in the study. In addition, the prevalence of raised blood pressure raised blood glucose and raised total cholesterol were $34.3 \%, 6.5 \%$ and $6.5 \%$ respectively.

The prevalence of smoking among men in this study (6.4\%) was high compared to $2.0 \%$ in the Ghana STEPS Survey ${ }^{24}$ but less than $42 \%$ in a survey in Kerala, India 10 and $15.6 \%$ in Gambia. ${ }^{25}$ Smoking is generally five times more prevalent among males than females; however the gender gap declines with younger age. ${ }^{12}$ Tobacco affects health in many ways: through nicotine, tar and the effect of carbon monoxide in the smoke, on the function of the body.

The prevalence of smoking in this study is comparable to the 2008 GDHS report which revealed that smoking in Ghana is higher among men $(6 \%)$ than women $(<0.5 \%)$. Almost all women and $93 \%$ of men said they did not use tobacco at all and only $6 \%$ of men age $15-49$ said they currently smoke cigarettes ${ }^{5}$ compared to $2.9 \%$ of women and $6.4 \%$ of men who smoked in this study. However since these figures are self-reported, they could have been underestimated.

The prevalence of alcohol consumption in this study was $64.8 \%$ with male and female prevalence of $72 \%$ and $56.19 \%$ respectively which was more than $35 \%$ in men and $18 \%$ in women in Ghana in $2008 .^{5}$ This was also more than the prevalence in the Ghana STEPS Survey $(30.9 \%)^{24}$, among middle-income free-living urban population in India:7.1\%-males and 3.1\%-females ${ }^{13}$ as well as a population prevalence of $10 \%$ in a study in Kerala, India. ${ }^{10}$

Alcohol consumption was significantly related to sex, age and work status but not evident with marital status and level of education. However those with highest education consumed less alcohol than those with some education and this could be due to their busy academic schedules, giving them little time to socialize. 'In addition to the toxicity of excessive alcohol intake, there is also the possibility of long term damage to the nervous system, liver and other organs. 
Prevalence of physical inactivity among the respondents in this study was $54.30 \%$ which was lower than that of the Ghana STEPS Survey (76.7\%) and higher than similar study conducted in Vietnam with $34.71 \%{ }^{11}$ and rural area of Kerala, India with $9.5 \%{ }^{10}$ Physical inactivity was significantly associated with work status but not related to obesity, diabetes and dyslipidaemia.

Considering the educational level, the prevalence of educated individuals who consumed alcohol (26\%) was slightly less than individuals with no formal education $(27.1 \%){ }^{14}$ The prevalence of obesity, which is a potentially modifiable risk factor for non-communicable diseases ${ }^{15}$ in the study was $40.4 \%$, which was greater than $14.1 \%$ in a study in rural and urban Accra ${ }^{4}$ and 5.5\% among Ghanaians ${ }^{16}$ as well as $9 \%$ in the GDHS. ${ }^{5}$

This high prevalence of obesity in our sample is an approximate representative of hospital attendance. The prevalence of central obesity was however lower and indicates both subcutaneous and intraabdominal tissue, which if high could increase the risk of cardiovascular diseases. Obesity was significantly associated with raised blood pressure, marital status and work status. Our findings are similar to a report from Vietnam, ${ }^{11}$ where obesity increased linearly with hypertension.

The high prevalence of obesity in the study could be due primarily to lack of physical activity and also unhealthy eating habits among patients reporting to the surgical and medical departments of the hospital. Obesity is by far the most important risk factor for type 2 diabetes. ${ }^{13}$ The prevalence of raised blood glucose (6.5\%) which was significantly associated with age and raised blood pressure, was high in Greater Accra (6.3\%) compared to reports from Vietnam (1.62\%), Maldives $(4.7 \%)^{18}$ and lower than the report of a study in the United States $(19.8 \%) .{ }^{19}$ The lipid profile examined consisted of total cholesterol, triglycerides, HDL-cholesterol and LDLcholesterol.

The prevalence of raised total cholesterol was $6.5 \%$, which was relatively lower than a study in Vietnam (20.45\%) and in Haryanna (44.8\%). Moderate amount of alcohol is known to increase the HDL- cholesterol, which has cardio protective effects. 20, 21 Obese individuals were the highest respondents with raised total cholesterol.

Although there was a significant association between raised cholesterol and tobacco use, there was no association with obesity, raised blood pressure and glucose levels. Tobacco use is a major cause of stroke by increasing clotting factors in the blood, decreasing HDL cholesterol levels, increasing triglyceride levels, and damaging the lining of vascular endothelium. ${ }^{22}$

Prevalence of hypertension in this study was $34.3 \%$ with relatively no difference among the sexes, similar to previous reports from Ga district $(25.4 \%)$, Volta Region $(32.8 \%)^{23}$ and Greater Accra Region (36.7\%) ${ }^{24}$, all in Ghana and comparable to $33.1 \%$ reported from Botswana. ${ }^{26}$ However the prevalence of raised systolic and raised diastolic blood pressure in the study was relatively similar. It was also observed in this study that raised blood pressure was significantly associated with age, alcohol consumption and physical inactivity. Hypertension was associated with raised blood glucose, a trend similar to a study in India. In this study, the prevalence of fruit intake was $70.87 \%$ which was more than a study in Vietnam $(24.34 \%)$.

This may be because patients are well informed of the importance or widespread availability of fruits and vegetables in their diet. Almost $62 \%$ of the participants had raised risk, defined as combination of three or more risk factors, which was low compared to $56 \%$ in the Greater Accra Region of Ghana. ${ }^{24}$

Generally the prevalence among the hospital populace was higher compared to the general population studies probably due to the existence of the risk factors among the new attendants and also due to the relatively smaller sample size of study participants.

\section{CONCLUSION}

In conclusion, this study conducted in the Surgical and Medical Out-Patients Department (OPD) of the Korle-Bu Teaching Hospital, provided the prevalence of various risk factors among patients reporting primarily without knowledge of the risk factors. The high prevalence of alcohol, physical inactivity, overweight and relatively high prevalence of hypertension is of public health concern, which must be addressed immediately. Hospitals should include NCD risk factor monitoring as part of routine services to avoid missed opportunities. The significant risk factors in this study were physical inactivity, alcohol consumption, overweight, obesity and raised blood pressure.

Due to the high prevalence of some of these risk factors, it is essential to closely monitor them, hence controlling prevalence of non-communicable diseases such as cardiovascular, diabetes, chronic obstructive pulmonary disease, cancers and other injuries. The compilation of risk factor prevalence over a period of time would give an idea of the prevailing problem. 
Also parents attending paediatric wards should also have these risk factors checked to avoid missed opportunity.

\section{REFERENCES}

1. World Health Organization, Noncommunicable diseases and mental health: Global status report on non-communicable diseases, their risk factors and determinants; 2010.

2. World Health Organization Report 2000Health Systems: Improving Performance, Geneva; 2000.

3. Schuit AJ, Van Loon AJ, Tijhuis M, Ocke M, Clustering of lifestyle risk factors in a general adult population, Prev Med. 2002; (35):21924 .

4. Amoah AG, Obesity in adult residents of Accra, Ghana, Ethnicity and Disease. 2003; 13(2 Suppl 2):S29-S101.

5. Ghana Statistical Service, Characteristics of survey respondents In Ghana Demographic and Health Survey. 2008; p 59-61.

6. Amoah AG, Owusu SK, Adjei S, Diabetes in Ghana: a community based prevalence study in Greater Accra, Diabetes Res and Clin Prac. 2002; 56(3):197-205.

7. Addo J, Amoah A G, Koram KA, The changing patterns of hypertension in Ghana: a study of four rural communities in the $\mathrm{Ga}$ District, Ethnicty and Disease. 2006; 16(4):894-9.

8. Korle-Bu Teaching Hospital, Introduction and Background In Annual Report 2008; p x.

9. U.S Department of Health and Human Services, The $7^{\text {th }}$ Report of the Joint National Committee on Prevention, Detection, Evaluation and Treatment of High Blood Pressure. 2004; p 12.

10. Thankappan K.R, Bela Shah, Prashant Mathur, P.S. Sarma, G. Srinivas, G.K. Mini, Meena Daivadanam Biju Soman \& Ramachandran S. Vasan, Risk factor profile for chronic non-communicable diseases: Results of a community-based study in Kerala, India, Indian Journal of Medical Research. 2009; p 53-63.

11. Pham LH, Au TB, Blizzard L, Truong NB, Schmidt MD, Granger RH, Dwyer T, Prevalence of risk factors for noncommunicable diseases in the Mekong Delta, Vietnam: results from a STEPS survey, $B M C$ Public Health. 2009;12(9)291.

12. Guindon, G. Emmanuel; Boisclair, David, Past, current and future trends in tobacco use. Washington DC: The International Bank for
Reconstruction and Development / The World Bank.2003; p 13-16.

13. Meenakshi Bakshi Mehan, Somila Surabhi, Gautami T Solanki, Risk factor profile of non-communicable diseases among middle-income (18-65 years) freeliving urban population of India, International Journal of Diabetes in Developing Countries. 2006 ;(4)169176.

14. U.S National Institute of Health, Blood Vessels \& Aging: The Rest of the Journey In Aging Hearts \& Arteries: A Scientific Quest; 2008.

15. Pinckney J, Prevention and cure of type 2 diabetes. $\mathrm{Br}$ Med J. 2002; 325(7358):232-3.

16. Biritwum R.B, Gyapong J, Mensah G, The epidemiology of Obesity in Ghana, Ghana Medical Journal. 2005; 39(3):1.

17. Popkin BM, Gordon-Larsen $\mathrm{P}$, The nutrition transition: worldwide obesity dynamics and their determinants, International journal of obesity and related metabolic disorders. 2004;28(3):S2-9.

18. Aboobakur M, Latheef A, Mohamed AJ, Moosa S, Pandey RM, Krishnan A, Prabhakaran D, Surveillance for non-communicable disease risk factors in Maldives: results from the first STEPS survey in Male, International Journal of Public Health. 2010; 55(5): 489-96.

19. World Health Organization Report - Issues of Communication and Risk, Non-communicable Diseases \&Mental Health(NMH) Communications at the World Health Organization; 2002.

20. Klatsky A.L, Alcohol and Cardiovascular Diseases In Alcohol in Health and Diseases, New York Marcel Dekker. 2001; p 517-546.

21. Weeks DL, Daratha KB, Towle LA, Diabetes prevalence and influence on resource use in Washington state inpatient rehabilitation facilities, 2001 to 2007, Archives of Physical Medicine and Rehabilitation.2009;90(11):1937-43.

22. Van Tol, A and Hendriks, H.F, Moderate alcohol consumption, effects on lipids and cardiovascular disease risk ,Curr Opin Lipidol .2001;12:19-23.

23. Brent A.Burket, Blood pressure survey in two communities in the Volta Region, Ghana, West Africa, Ethnicity and Disease, vol.16; 2006.

24. Ghana Health Survey, Ghana STEPS Survey-Greater Accra Region 2006.

25. World Health Organization, Tobacco Surveys of adult tobacco use in WHO member states globally In Report on the Global Tobacco Epidemic, - Gambia STEPS Survey ; 2011.

26. World Health Organization, Botswana STEPS Survey Fact Sheet: 2007, p.1-2. Available from http ://www.afro.who.int.

27. Ama de-Graft Aikins, Ghana's neglected chronic disease epidemic: a developmental challenge, Ghana Medical Journal. 2007;41(4):154-159 
